\title{
Cesarean Section Rate in a Sample of Primigravida Women in the Public Maternity Hospital in Erbil City, Iraq
}

\author{
Shahla Mehedi ${ }^{1}$, Jawad Al-Diwan ${ }^{2}$, Tariq Al-Hadithi ${ }^{3 *}$
}

\begin{abstract}
Objectives: The worldwide rise in the cesarean section rates might be associated with maternal factors and health care services. This study aimed to measure the rate of cesarean section in a sample of primigravida women and find out the association of the cesarean section rate with the socio-demographic characteristics of pregnant women, pregnancy risk factors, and the utilization of antenatal care services.

Materials and Methods: A cross-sectional study was carried out from the 1st of July, 2015 to 30th of June, 2016. The study sample included 400 primigravida women with singleton pregnancy at the labor room of Erbil Maternity Teaching Hospital. A specially designed questionnaire was used for data collection. Chi-square test and Fishers exact test were used for statistical analyses.

Results: The rate of cesarean section in the primigravida women was $30 \%$. Caesarean section was significantly associated with the increasing maternal age $(P<0.001)$ and the history of treatment for infertility $(P=0.027)$. The cesarean section rates had a statistically significant $(P<0.001)$ strong positive correlation $(\mathrm{r}=0.84)$ with the maternal age and a significant $(P<0.001)$ weak positive correlation $(r=0.005)$ with the gestational age.

Conclusions: The cesarean section rate in the primigravida women was much higher than the "ideal rate" recommended by the World Health Organization (WHO). Efforts should be undertaken to reduce the rate of cesarean delivery as recommended by the WHO.

Keywords: Cesarean section, Primigravida, Infertility, Singleton pregnancy, Erbil
\end{abstract}

\section{Introduction}

Cesarean section is usually performed when a vaginal delivery would put the baby's or mother's life or health at risk. Cesarean section can save lives, but it is frequently performed without medical indications (1). It is often done as an emergency procedure in women with cephalopelvic disproportion, obstructed labor, fetal distress, antepartum hemorrhage and previous cesarean section resulting in high perinatal and maternal morbidities (2).

Cesarean section rates have risen worldwide. A study that involved 150 countries reported a rate of $18.6 \%$ ranging from $6 \%$ in the least developed countries to $27.2 \%$ in the most developed countries. Cesarean section rates are highest in the Latin America and the Caribbean region (40.5\%) and Northern America (32.3\%), while they are lowest in Asia (19.2\%) and Africa (7.3\%) (3). In the Arab countries, cesarean section rates vary widely with Egypt having the highest cesarean section rate (26.2\%) and Mauritania the lowest (5.3\%) (4).

Studies from industrial countries have shown that the indications for the cesarean section have changed over the last decades and increased knowledge about current indications could lead to the reduction of cesarean section rates through correct counseling and advice to pregnant women and health workers (5-8).

The worldwide increase in cesarean section rate which might be associated with maternal factors and health care services provided the impetus for carrying out this study. It is important to ensure that a cesarean section is provided to women in real need. This study aimed to determine the rate of cesarean section in a sample of primigravida women and find out the association between the cesarean section rate and the socio-demographic characteristics of pregnant women, pregnancy risk factors, and the utilization of antenatal care services.

\section{Materials and Methods}

This cross-sectional study was conducted at Erbil Maternity Teaching Hospital in Kurdistan region of Iraq from 1st of July, 2015 to 30th of June, 2016. A sample of 400 primigravida women was selected for the study by convenient sampling technique. All the primigravida women who were present in Erbil Maternity Teaching Hospital in the days when the researcher was attending the hospital for data collection were invited to participate in the study. The study included the primigravida women

Received 6 March 2017, Accepted 20 October 2017, Available online 18 November 2017

${ }^{1}$ Directorate of Health, Mosul, Iraq. ${ }^{2}$ Baghdad University, Community Medicine, Baghdad, Iraq. ${ }^{3}$ Hawler Medical University, Community Medicine, Erbil, Iraq.

*Corresponding Author: Tariq Al-Hadithi, Email: talhadithi@yahoo.com 
who were above 24 weeks of gestation. Women with chronic diseases such as hypertension, cardiovascular disease, diabetes mellitus, renal disease, and bronchial asthma in addition to the women with multiple pregnancies or preeclampsia were excluded from the study.

A structured questionnaire was designed and field tested before using it to obtain the relevant data. The primigravida women were directly interviewed in the labor room or post labor wards of the hospital to collect the data. A detailed history was obtained and physical examination of each woman was performed. The hemoglobin level was measured for the participants and abdominal ultrasound was performed to ascertain the viability of the fetus and determine the gestational age. Caesarean section was taken as the dependent variable, while current maternal age, history of treatment for infertility, psychosocial stress, antenatal care, iron/folic acid supplementation, and anemia during the current pregnancy were considered as independent variables.

The Statistical Package for the Social Sciences (SPSS) version 21.0 was used for the statistical analysis. Chisquare analysis test and Fisher exact test, as relevant, were used. A $P$ value $\leq 0.05$ was considered statistically significant. The association of the cesarean section rates with the gestational and the maternal age was further analyzed by regression analysis.

\section{Results}

The mean age \pm SD of the study participants was $22.55 \pm$ 4.37, ranging from 15 years to 37 years. Antenatal care visits were reported by $390(97.5 \%)$ primigravida women with $271(69.5 \%)$ having adequate antenatal care (i.e., 4 visits and more) and 180 (46.2\%) starting the visits during the 1st trimester of pregnancy. Anemia was diagnosed in 108 (27\%) participants. One hundred twenty-three (30.8\%) primigravida women had cesarean section; 41 (33.3\%) of them were anemic and 30 (24.0\%) were infertile.

The most common indications for the cesarean section were cephalopelvic disproportion (21.1\%) and fetal distress $(21.1 \%)$. Mother's request for cesarean section constituted $7.3 \%$ of all cesarean sections (Table 1 ).

Caesarean section was significantly associated with increasing maternal age $(P<0.001)$ and history of treatment for infertility $(P=0.027)$ as shown in Table 2 .

There was a significant strong positive correlation between cesarean section rates and the maternal age (beta $=0.048 ; r=0.84 ; P<0.001$ ), while a significant weak positive correlation was detected between the cesarean section rates and the gestational age (beta $=0.3746 ; r=$ $0.005 ; P<0.001)$ as shown in Figures 1 and 2 .

\section{Discussion}

The rate of cesarean section has increased remarkably in Iraq in the recent years, particularly in the Kurdistan region of Iraq (9). A retrospective study based on the annual reports of Ministry of Health revealed an
Table 1: Indications for Cesarean Section of Study Sample, Maternity Teaching Hospital in Erbil City, 2015, $(n=123)$

\begin{tabular}{lc}
\hline Indications & No. (\%) \\
\hline Cephalopelvic disproportion & $26(21.1)$ \\
Fetal distress & $26(21.1)$ \\
Fetal malpresentation & $18(14.7)$ \\
Failure induction of labor & $17(13.8)$ \\
Severe oligohydramnios & $13(10.6)$ \\
Post date & $9(7.3)$ \\
Mother request & $9(7.3)$ \\
Placental causes & $4(3.3)$ \\
Cord prolapse & $1(0.8)$ \\
Total & $123(100.0)$ \\
\hline
\end{tabular}

Table 2. Association of Cesarean Section With Certain Sociodemographic and Obstetric Characteristics

\begin{tabular}{|c|c|c|c|c|}
\hline \multirow{2}{*}{ Variables } & \multirow{2}{*}{ No. } & \multicolumn{2}{|c|}{ CS } & \multirow{2}{*}{$P$} \\
\hline & & No. & $\%$ & \\
\hline \multicolumn{5}{|l|}{ Maternal age (y) } \\
\hline$<20$ & 62 & 9 & 14.5 & \multirow{3}{*}{$<0.001$} \\
\hline $20-34$ & 325 & 104 & 32.0 & \\
\hline$\geq 35$ & 13 & 10 & 76.9 & \\
\hline \multicolumn{5}{|c|}{ History of treatment for infertility } \\
\hline Yes & 72 & 30 & 41.7 & \multirow{2}{*}{0.027} \\
\hline No & 328 & 93 & 28.4 & \\
\hline \multicolumn{5}{|l|}{ Psychosocial stress } \\
\hline Yes & 42 & 11 & 26.2 & \multirow{2}{*}{0.498} \\
\hline No & 358 & 112 & 31.3 & \\
\hline \multicolumn{5}{|c|}{ Number of ANC visits $(n=390)$} \\
\hline$<4$ & 119 & 45 & 37.8 & \multirow{2}{*}{0.216} \\
\hline$\geq 4$ & 271 & 78 & 28.8 & \\
\hline \multicolumn{5}{|c|}{ Time of first ANC visit $(n=390)$} \\
\hline 1st trimester & 180 & 46 & 25.6 & \multirow{3}{*}{0.093} \\
\hline 2nd trimester & 171 & 57 & 33.3 & \\
\hline 3rd trimester & 39 & 16 & 41.0 & \\
\hline \multicolumn{5}{|l|}{ Blood transfusion } \\
\hline Yes & 11 & 7 & 63.6 & \multirow{2}{*}{0.040} \\
\hline No & 389 & 116 & 29.8 & \\
\hline \multicolumn{5}{|c|}{ Ferro-folic supplementation } \\
\hline Yes & 353 & 106 & 30.0 & \multirow{2}{*}{0.391} \\
\hline No & 47 & 17 & 36.2 & \\
\hline \multicolumn{5}{|l|}{ Anemia } \\
\hline Yes $(\mathrm{Hb}<11 \mathrm{~g} / \mathrm{dL})$ & 108 & 41 & 38.0 & \multirow{2}{*}{0.057} \\
\hline No & 292 & 82 & 28.1 & \\
\hline Total & 400 & 123 & 30.8 & \\
\hline
\end{tabular}

increasing trend in the overall cesarean section rate in public hospitals from $24.6 \%$ to $29.3 \%$ in 2012 and the private hospitals from $74.8 \%$ in 2009 to $77.9 \%$ in 2012 . The overall rates of cesarean section in Erbil governorate varied between $20.9 \%$ in 2008 and $37.6 \%$ in 2012. No specific data on each of the public or private sectors were available for Erbil governorate (10). The increased rates of cesarean section in the private health care sector were attributed to provider-induced demand (11). Presence of a large number of private hospitals in Iraq might be partially responsible for the increased rates of cesarean 


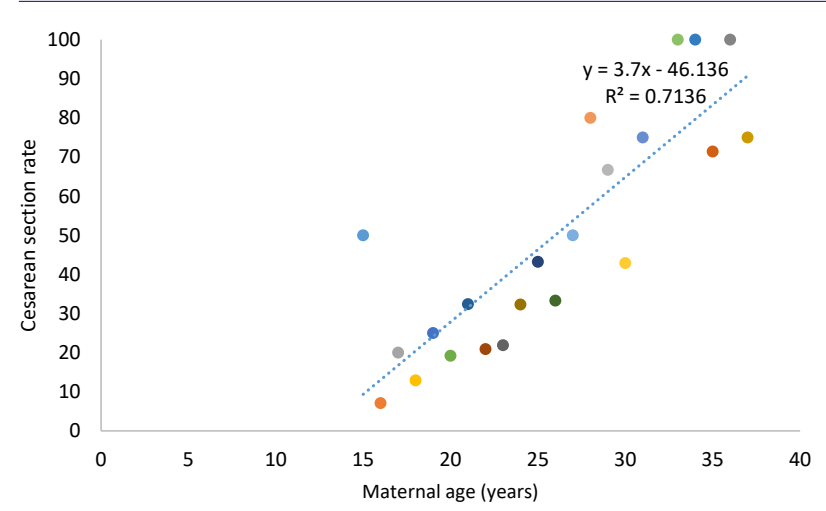

Figure 1. Regression Line Drawn on Scatter Diagram Relating Cesarean Section Rate and Maternal Age $(y=0.038 x+0.048, r$ $=0.84, P<0.001)$.

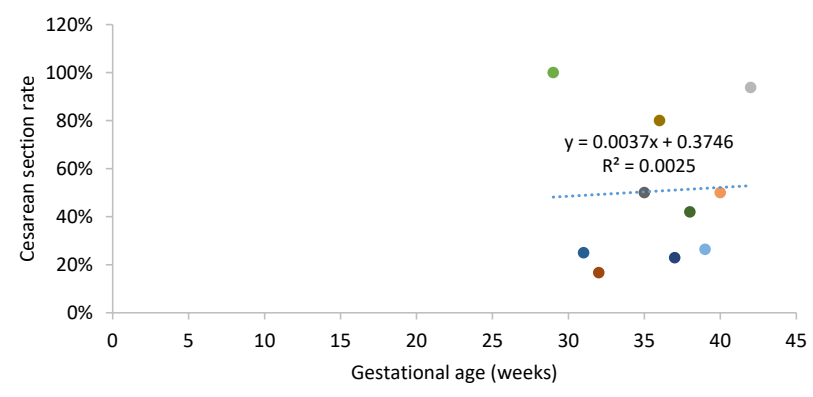

Figure 2. Regression Line Drawn on Scatter Diagram Relating Cesarean Section rate and Gestational Age $(y=0.0037 x+$ $0.3746, r=0.005, P<0.001)$.

section potentially due to provider-induced demand (9). Such factor might also be responsible for having a higher increase in the cesarean section rates in the Kurdistan region of Iraq, since the Kurdistan Region has witnessed a rapid expansion of the private healthcare sector which is poorly regulated (12).

The rate of cesarean section revealed by this study (30.8\%) was similar to that reported in Iraq in the public hospitals in 2012 (29.3\%) (10). The rate was higher than the rate in some neighboring countries including Turkey (21.2\%) and Jordan (18.5\%). However, a higher rate of $41.9 \%$ was reported in Iran (13).

This cesarean section rate revealed in this study was much higher than the optimal rate of $10 \%(1,14)$. However, the World Health Organization (WHO) stated that the "ideal rate" for cesarean section is to be between $10 \%$ and $15 \%$, but when the rate goes above $10 \%$, there is no evidence that maternal and neonatal mortality rates improve (1). Identifying and addressing these risk factors need setting policies to reduce surgical deliveries $(4,11)$.

This study revealed that medical reasons constituted the vast majority of the indications for the high rate of cesarean section, which cannot be avoided. However, obstetricians' opinion about the urgent need for cesarean section and maternal request are other factors responsible also for the relatively high proportion of the indications for elective surgery, which can be avoided. The common maternal request has constituted variable proportions of elective cesarean section $(7,8,15)$. It is worth to mention that in Kurdistan region, assisted vaginal delivery such as forceps delivery and vacuum extraction is not a common practice as the majority of senior house officers are not well trained and not allowed to carry out the procedure. Consequently, the procedure is carried out only by trained specialists and consultants. This may have contributed to having a high rate of cesarean section. For example, the rate of the operative vaginal delivery in the United States is around $5 \%(16)$.

In this study, cesarean section was significantly associated with increased maternal age, a finding which is in agreement with that of studies conducted in Nigeria in 2011 (17) and the United Kingdom in 2013 (18). Advanced maternal age can be associated with a number of maternal and neonatal complications and consequences including gestational diabetes, placenta previa, abruptio placenta, pre-eclampsia, cesarean section, stillbirth, preterm delivery, low birth weight and increased perinatal mortality (19). The significant association between cesarean section and the history of treatment for infertility was similarly revealed by a study in Israel on nulliparous women with singleton pregnancies (20). This finding could be attributed to maternal request and the increased concerns of the family about the safety of the baby. In this study, a statistically significant association between cesarean section and higher mean gestational age was demonstrated. In a study that involved 17 European countries and the United States, the cesarean section rate was negatively associated with the increasing gestational age with the lowest rate being at 40 weeks of gestation. The rate typically increased at 41 and 42 weeks (21).

This study has two main limitations. Firstly, selection of a convenient sample limits the representativeness of the sample to all women attending the hospital. Secondly, the inclusion of only one center in the study would affect the generalizability of the findings.

\section{Conclusions}

The cesarean section rate in the primigravida women was much higher than the "ideal rate" recommended by the WHO. Efforts should be undertaken to reduce the rate of cesarean delivery according to WHO recommendations. There is a need for a larger study sample to determine the association of other risk factors with pregnancy outcomes.

\section{Conflict of Interests}

Authors declare that they have no conflict of interests.

\section{Ethical Issues}

The study was reviewed and approved by the Research Ethics Committee of the author's institution and the informed consent was obtained from the participants. 


\section{Financial Support}

None.

\section{References}

1. WHO. WHO statement on caesarean section rates. 2015. http://www.who.int/reproductivehealth/publications/ maternal_perinatal_health/cs-statement/en/.

2. Ugwa E, Ashimi A, Abubakar MY. Caesarean section and perinatal outcomes in a sub-urban tertiary hospital in North-West Nigeria. Niger Med J. 2015;56(3):180-184. doi:10.4103/0300-1652.160360

3. Betran AP, Ye J, Moller AB, Zhang J, Gulmezoglu AM, Torloni MR. The Increasing Trend in Caesarean Section Rates: Global, Regional and National Estimates: 1990-2014. PLoS One. 2016;11(2):e0148343. doi:10.1371/journal. pone. 0148343

4. Khawaja M, Choueiry N, Jurdi R. Hospital-based caesarean section in the Arab region: an overview. East Mediterr Health J. 2009;15(2):458-469.

5. Wax JR, Cartin A, Pinette MG, Blackstone J. Patient choice cesarean: an evidence-based review. Obstet Gynecol Surv. 2004;59(8):601-616.

6. Black C, Kaye JA, Jick H. Cesarean delivery in the United Kingdom: time trends in the general practice research database. Obstet Gynecol. 2005;106(1):151-155. doi:10.1097/01.AOG.0000160429.22836.c0

7. ACOG Committee Opinion No. 394, December 2007. Cesarean delivery on maternal request. Obstet Gynecol. 2007;110(6):1501. doi:10.1097/01. AOG.0000291577.01569.4c

8. Robson S, Carey A, Mishra R, Dear K. Elective caesarean delivery at maternal request: a preliminary study of motivations influencing women's decision-making. Aust N Z J Obstet Gynaecol. 2008;48(4):415-420. doi:10.1111/ j.1479-828X.2008.00867.x

9. Shabila NP. Rates and trends in cesarean sections between 2008 and 2012 in Iraq. BMC Pregnancy Childbirth. 2017;17(1):22. doi:10.1186/s12884-016-1211-6

10. Mohsen Ali R, Fadhil SN. Incidence of Caesarean Section in AL-Elwyia Maternity Teaching Hospital: Retrospective Study. IOSR Journal Nursing Health Science. 2015;4(4):6067. doi:10.9790/1959-04426067

11. Roberts CL, Algert CS, Ford JB, Todd AL, Morris JM.
Pathways to a rising caesarean section rate: a populationbased cohort study. BMJ Open. 2012;2(5). doi:10.1136/ bmjopen-2012-001725

12. Anthony CR, Moore M, Hilborne LH, Mulcahy AW. Health Sector Reform in the Kurdistan Region - Iraq: Financing Reform, Primary Care, and Patient Safety. Rand Health Q. 2014;4(3):2.

13. Gibbons L, Belizan JM, Lauer JA, Betran AP, Merialdi M, Althabe F. The global numbers and costs of additionally needed and unnecessary caesarean sections performed per year: overuse as a barrier to universal coverage. World Health Report. 2010;30:1-31.

14. Ye J, Zhang J, Mikolajczyk R, Torloni MR, Gulmezoglu AM, Betran AP. Association between rates of caesarean section and maternal and neonatal mortality in the 21st century: a worldwide population-based ecological study with longitudinal data. Bjog. 2016;123(5):745-753. doi:10.1111/1471-0528.13592

15. Tranquilli AL, Giannubilo SR. Cesarean delivery on maternal request in Italy. Int J Gynaecol Obstet. 2004;84(2):169-170. doi:10.1016/s0020-7292(03)00319-9

16. Ali UA, Norwitz ER. Vacuum-assisted vaginal delivery. Rev Obstet Gynecol. 2009;2(1):5-17.

17. Ojule JD, Ibe VC, Fiebai PO. Pregnancy outcome in elderly primigravidae. Ann Afr Med. 2011;10(3):204-208. doi:10.4103/1596-3519.84699

18. Khalil A, Syngelaki A, Maiz N, Zinevich Y, Nicolaides KH. Maternal age and adverse pregnancy outcome: a cohort study. Ultrasound Obstet Gynecol. 2013;42(6):634-643. doi:10.1002/uog.12494

19. Laopaiboon $M$, Lumbiganon $P$, Intarut $N$, et al. Advanced maternal age and pregnancy outcomes: a multicountry assessment. BJOG. 2014;121 Suppl 1:49-56. doi:10.1111/1471-0528.12659

20. Sheiner E, Shoham-Vardi I, Hershkovitz R, Katz M, Mazor M. Infertility treatment is an independent risk factor for cesarean section among nulliparous women aged 40 and above. Am J Obstet Gynecol. 2001;185(4):888-892. doi:10.1067/mob.2001.117308

21. Delnord M, Blondel B, Drewniak N, et al. Varying gestational age patterns in cesarean delivery: an international comparison. BMC Pregnancy Childbirth. 2014;14:321. doi:10.1186/1471-2393-14-321

(c) 2018 The Author (s); This is an open-access article distributed under the terms of the Creative Commons Attribution License (http://creativecommons.org/licenses/by/4.0), which permits unrestricted use, distribution, and reproduction in any medium, provided the original work is properly cited. 